\title{
Predominance of synovial sensory nerve fibers in arthrofibrosis following total knee arthroplasty compared to osteoarthritis of the knee
}

Franz Xaver Koeck ${ }^{1 *+}$, Miriam Schmitt ${ }^{2+}$, Clemens Baier $^{3}$, Hubert Stangl ${ }^{2}$, Johannes Beckmann ${ }^{4}$, Joachim Grifka ${ }^{3}$ and Rainer H. Straub²

\begin{abstract}
Background: So far, there exists no golden standard for the treatment of arthrofibrosis (AF) following total knee arthroplasty (TKA). Although pain is a hallmark of AF, nociceptive nerve fibers have never been investigated in affected joint tissue.

Methods: A total of 24 patients with osteoarthritis $(\mathrm{OA})$ of the knee $(n=12)$ and post-TKA AF of the knee $(n=12)$ were included. Along evaluation of typical clinical signs and symptoms by using the Knee Society Clinical Rating System (KSS), the Knee Injury and Osteoarthritis Outcome Score (KOOS), and the Western Ontario and McMaster Universities Osteoarthritis Index (WOMAC index), the innervation of joint tissue was studied by semiquantitative immunofluorescence of nerve fibers.

Results: Patients with AF compared to OA had a lower KSS and lower KOOS. In all compartments (anterior, medial, and lateral recesses), the density of synovial sympathetic nerve fibers was significantly higher in OA compared to $A F$, which was also true for the density of sensory nerve fibers in the medial and lateral recesses. In synovial tissue of the anterior recess of patients with AF compared to OA, the density of nociceptive sensory nerve fibers was significantly higher relative to sympathetic nerve fibers. This was similarly observed in the neighboring infrapatellar fat pad of the knee.
\end{abstract}

Conclusions: Similar as in many painful musculoskeletal diseases, this study indicates that patients with arthrofibrosis of the knee after TKA demonstrate a preponderance of profibrotic sensory nerve fibers over antifibrotic sympathetic nerve fibers. This could serve as a starting point for AF therapy with specific antifibrotic pain medication or regional anesthetic techniques.

Keywords: Arthrofibrosis, Knee, Osteoarthritis, Arthroplasty, Nerve fibers

\section{Background}

Arthroplasty is a safe and satisfactory procedure in the therapy of degenerative knee pathologies. Most people experience great benefit with regard to mobility and quality of life even in long-term follow-up after total knee arthroplasty (TKA) [1, 2]. Nevertheless, reduced motion and stiffness can be a frustrating complication

\footnotetext{
* Correspondence: f.x.koeck@medartes.de

${ }^{\dagger}$ Equal contributors

${ }^{1}$ MedArtes - Private Orthopaedic Clinic, Regensburger Strasse 13, 93073

Neutraubling, Germany

Full list of author information is available at the end of the article
}

for both, the patient and the surgeon. This is often linked to persistent pain and marked functional problems. Since the beginning of the 1990s, stiffness due to an exaggerated scar formation as observed after anterior cruciate ligament reconstruction was called arthrofibrosis of the knee [3]. In the context of TKA, prevalence of arthrofibrosis (AF) ranges between 1.5 and $4.5 \%$ of all TKA operations $[4,5]$. Although no consensus as to the treatment of AF exists, four major procedures are used in patients with AF: (1) closed manipulation under anesthesia [6], (2) arthroscopic debridement and lysis 
[7], (3) open debridement and lysis of scar tissue, and (4) revision arthroplasty $[8,9]$. However, it is well known that each kind of manipulation including revision surgery means additional mechanical stress, which is afflicted with a high risk of recurrence of fibrosis [6]. Also, increased psychological distress is supposed to be a risk factor for postoperative stiffness in TKA [10]. While these problems are recognized, the etiology of postoperative AF is not well understood.

There are several important starting points in the etiology of AF. Activation of the fibroblast and myofibroblast is an important aspect with increased production of collagen type VI [11], alpha-smooth muscle protein [12], $\beta$-catenin [13], reactive oxygen and nitrogen species (also in macrophages and neutrophils) [14], and bone morphogenic protein type II [15]. The proinflammatory cytokine interleukin (IL)-1 $\beta$ might also play a role since injection of anakinra, the IL-1 receptor antagonist, was effective in an open study in AF patients [16]. Contiguous to fibroblasts, also profibrotic mast cells and $\mathrm{T}$ lymphocytes are involved in the scaring process in AF [17, 18]. Under experimental conditions in animals, transforming growth factor beta and vascular endothelial growth factor were found to be associated with fibrosis $[19,20]$. In addition, sonographic studies in humans demonstrated increased neovascularization in the synovial tissue and infrapatellar fat pad (Hoffa) [4]. All these factors relevant for a profibrotic process demonstrate a continuous smoldering low-grade inflammation characterized as a new type of synovialitis [13].

Notwithstanding the enormous progress made, it remains unclear why AF is painful and why this may be linked to scar formation. Articular pain is signaled to the central nervous system via peripheral sensory nociceptive nerve fibers, which are equipped with the major neurotransmitter substance P [21].

In patients with TKA-derived AF of the knee (controls: OA patients), this study was initiated to investigate, in parallel, the density of peripheral sensory nociceptive nerve fibers and the density of peripheral sympathetic nerve fibers in synovial tissue of the knee joint. Patients were characterized by classical instruments such as the Knee Society Clinical Rating System (KSS), the Knee Injury and Osteoarthritis Outcome Score (KOOS), and the Western Ontario and McMaster Universities Osteoarthritis Index (WOMAC index) [22-24]. The proliferative process in articular tissue was estimated by cellular density, which was a perfect marker of synovialitis related to AF [13].

\section{Methods}

A total of 24 patients with OA of the knee $(n=12)$ and AF after TKA $(n=12)$ were included. The characteristics of the patients are given in Table 1. The two groups were not different in age, sex, and systemic inflammation measured by the erythrocyte sedimentation rate or Creactive protein (Table 1 ).

The patients with knee OA underwent primary total knee joint replacement surgery, and the patients with AF underwent open revision with debridement and lysis of scar tissue. All patients were informed about the purpose of the study and gave written consent. The study was approved by the Ethical Committee of the University of Regensburg (No. 11-101-0220).

Severity of joint disease was characterized by the KSS, the KOOS, and the WOMAC index according to standard questionnaires [22-24]. The KSS is a simple but objective scoring system to rate the knee and patient's functional abilities such as walking and stair climbing before and after TKA [22-24]. The KOOS is developed as an extension of the WOMAC index with the purpose of evaluating short-term and long-term symptoms and function in subjects with knee injury and osteoarthritis. It holds five subscales: pain other symptoms, function in daily living, in sport, and recreation, and knee-related quality of life [22-24]. The WOMAC osteoarthritis index assesses pain, stiffness, and physical function in patients with hip and/or knee OA. It consists of 24 items divided into three subscales (pain, stiffness, and physical function) [22-24].

Although knowing that OA and AF might not differ much in expression of joint complaints and signs of inflammation, we studied these two independent patients groups in order to present comparative groups.

The preparation of the tissue for histology was as described [25]. Fat tissue of the infrapatellar fat pad and synovial tissue of the medial, lateral, and anterior recesses of the knee joint were used for histology. Samples intended for the determination of cell density and detection of nerve fibers were fixed, depending on sample size, for 18 to $48 \mathrm{~h}$ in phosphate-buffered saline (PBS) containing $3.7 \%$ formaldehyde and then incubated in PBS with $20 \%$ sucrose for 18 to $48 \mathrm{~h}$. Thereafter, the tissue was embedded in Tissue Tek (Tissue Tek, Sakura Finetek, Zoeterwoude, The Netherlands) and quickfrozen floating on liquid nitrogen.

Histological evaluation has been described in an earlier study [26]. Briefly, the frozen tissue samples were cut into 8-9- $\mu \mathrm{m}$-thick sections, and cell density was evaluated using DAPI (4',6-diamidino-2-phenylindol) staining. Cellular density in the tissue was determined by counting stained cells in 17 randomly selected highpower fields $(400 \times)$ and expressed per square millimeter.

The determination of synovial innervation has been described previously [25]. We used a primary antibody against tyrosine hydroxylase $\left(\mathrm{TH}^{+}\right.$, the key enzyme for $\mathrm{NE}$ production in sympathetic nerve endings, cat. no. AB152, Chemicon, Temecula, CA, USA) and against 
Table 1 Characteristics of patients under study

\begin{tabular}{lll}
\hline & Osteoarthritis of the knee & Arthrofibrosis of the knee \\
\hline Number of patients & 12 & 12 \\
Age, year & $69.2 \pm 2.4[59-86]$ & $66.4 \pm 2.4[55-77]$ \\
Gender, men/women & $3 / 9(25 / 75)$ & $4 / 8(33 / 67)$ \\
Indication for operation & 12, primary total knee arthroplasty & 12 , revision after total knee arthroplasty \\
Affected side, right/left & $6 / 6$ & $7 / 5$ \\
C-reactive protein, mg/l & $3.2 \pm 0.6[0.4-7.2]$ & $8.0 \pm 2.9[0.7-36.6]$ \\
Erythrocyte sedimentation rate, $\mathrm{mm}$ 1st hour & $8 \pm 2[2-19]$ & $21 \pm 8[2-76]$ \\
\hline
\end{tabular}

Data are given as means \pm SEM, percentages in parentheses, and ranges in brackets

substance $\mathrm{P}\left(\mathrm{SP}^{+}\right.$, the key neurotransmitter of $\mathrm{SP}^{+}$sensory nerve fibers, cat. no. AB1977, Chemicon). We used an Alexa 546-conjugated secondary antibody (cat. no. A11010, goat against rabbit IgG, Molecular Probes, Leiden, The Netherlands) to achieve immunofluorescent staining of sympathetic and sensory substance P-positive nerve fibers (Fig. 1).

The numbers of $\mathrm{TH}^{+}$sympathetic and $\mathrm{SP}^{+}$sensory nerve fibers per square millimeter were determined by averaging the number of stained nerve fibers (typical bead chain structure with at least four separated vesicles along the axon, minimum length $50 \mu \mathrm{m}$, determined by a micrometer eyepiece) in 17 randomly selected highpower fields of view $(400 \times)$. We controlled the positive nerve fiber staining by incubating the tissue with polyclonal control antibodies which always yielded a negative result (no red fluorescent staining).

All data are given as mean \pm SEM. Box plots give the 10th, 75th, 50th (median), 25th, and 10th percentile. Group medians were compared by the non-parametric Mann-Whitney test (SPSS/PC, Advanced Statistics, V18.0, SPSS Inc., Chicago). $p<0.05$ was the significance level. Due to the explorative nature of the study, we did not adjust for multiple use of the same data.

\section{Results}

The patients with AF demonstrated a significantly higher Knee Society knee score than the OA patients (Table 2). In addition, the AF compared to the OA patients demonstrated a significantly reduced knee-related quality of

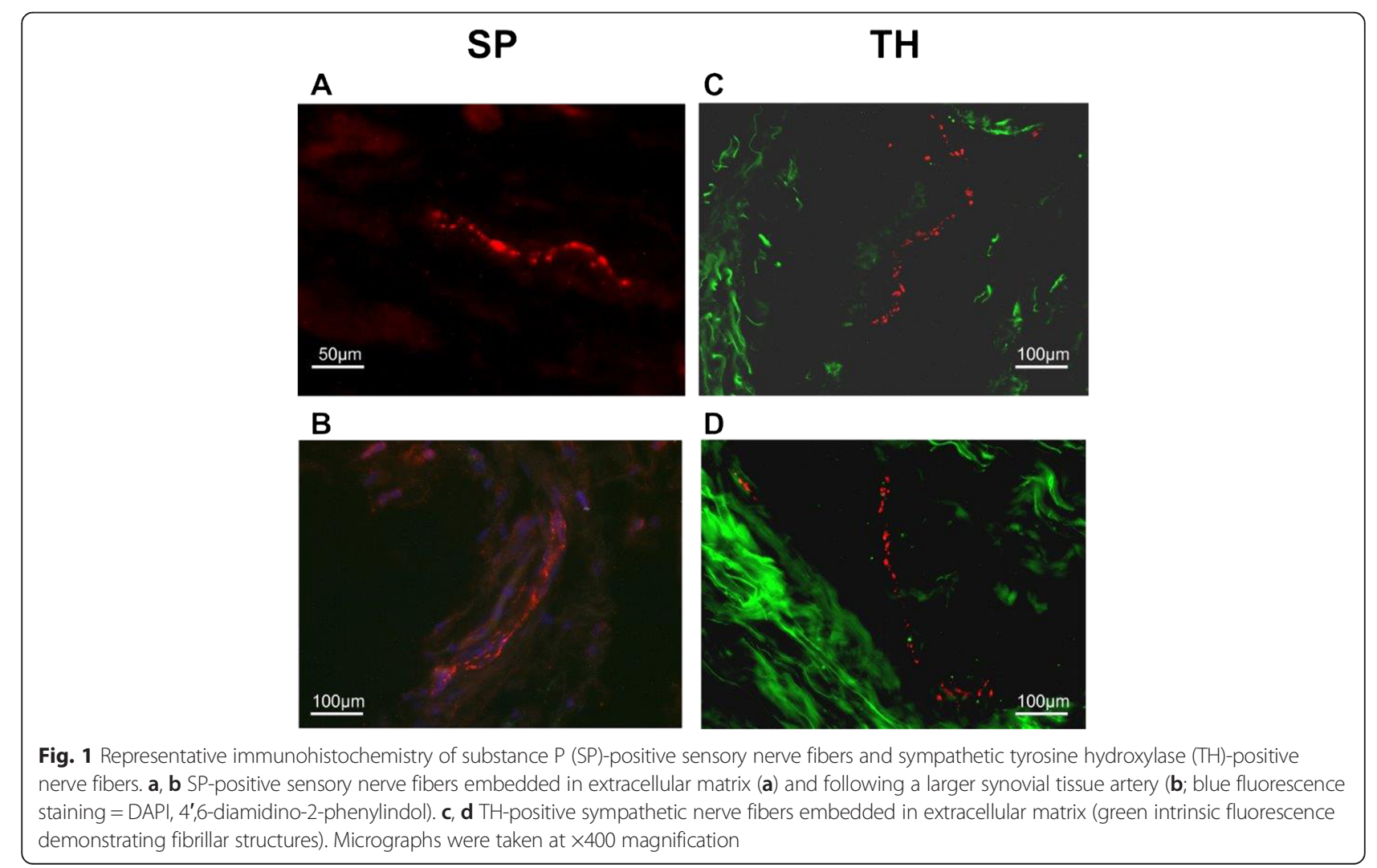


Table 2 Clinical parameters of patients under study

\begin{tabular}{|c|c|c|}
\hline & $\begin{array}{l}\text { Osteoarthritis of } \\
\text { the knee }\end{array}$ & $\begin{array}{l}\text { Arthrofibrosis of } \\
\text { the knee }\end{array}$ \\
\hline Knee Society knee score, points & $43 \pm 5$ & $33 \pm 3^{*}$ \\
\hline $\begin{array}{l}\text { Knee Society function } \\
\text { score, points }\end{array}$ & $52 \pm 5$ & $47 \pm 6$ \\
\hline KOOS pain, points & $38 \pm 4$ & $28 \pm 4^{* *}$ \\
\hline KOOS other symptoms, points & $43 \pm 4$ & $33 \pm 4$ \\
\hline $\begin{array}{l}\text { KOOS function in daily living, } \\
\text { points }\end{array}$ & $36 \pm 4$ & $29 \pm 5$ \\
\hline $\begin{array}{l}\text { KOOS function in sport and } \\
\text { recreation, points }\end{array}$ & $7.5 \pm 2.8$ & $2.5 \pm 1.1$ \\
\hline $\begin{array}{l}\text { KOOS knee-related quality } \\
\text { of life, points }\end{array}$ & $23 \pm 3$ & $15 \pm 4^{*}$ \\
\hline WOMAC pain, points & $11 \pm 1$ & $13 \pm 1$ \\
\hline WOMAC stiffness, points & $5.0 \pm 0.4$ & $5.7 \pm 0.4$ \\
\hline WOMAC function, points & $42 \pm 2$ & $47 \pm 3$ \\
\hline WOMAC total, points & $58 \pm 4$ & $65 \pm 4$ \\
\hline $\begin{array}{l}\text { Thigh circumference } 20 \mathrm{~cm} \\
\text { above knee, cm }\end{array}$ & $55 \pm 3$ & $52 \pm 2$ \\
\hline $\begin{array}{l}\text { Thigh circumference } 10 \mathrm{~cm} \\
\text { above knee, } \mathrm{cm}\end{array}$ & $48 \pm 3$ & $45 \pm 1$ \\
\hline $\begin{array}{l}\text { Thigh circumference at knee } \\
\text { joint, } \mathrm{cm}\end{array}$ & $43 \pm 1$ & $43 \pm 1$ \\
\hline
\end{tabular}

Data are given as means \pm SEM, percentages in parentheses, and ranges in brackets

KOOS Knee Injury and Osteoarthritis Outcome Score

${ }^{*} p<0.05 ;{ }^{* *} p=0.072$ for comparison of the two groups

life as estimated using the KOOS questionnaire (Table 2). In a form of a trend, pain appeared more severe in the patients with AF compared to OA, however not significantly (Table 2).

In all recesses (anterior, medial, lateral), the synovial density of sympathetic nerve fibers was significantly higher in the OA compared to the AF patients (Fig. 2a). Similarly, in the medial and lateral recesses, the synovial density of substance P-positive sensory nerve fibers was significantly higher in OA compared to AF (Fig. 2b). This indicates that the scaring tissue in AF contains less sympathetic and sensory nerve fibers compared to the OA control group (Fig. 2).

In order to study a preponderance of a nerve fiber type over the other, ratios were generated in every patient with the density of substance P-positive nerve fibers in the nominator and the density of sympathetic nerve fibers in the denominator $[25,27]$. In the anterior recess of the knee, this particular ratio was higher in the patients with AF compared to the patients with OA (Fig. 3). Although a similar trend existed for the medial and lateral recesses of the knee, this did not reach a significant level (Fig. 3).

Since the phenomenon of sensory hyperinnervation in relation to sympathetic innervation was mainly detected in the anterior recess of the knee, additional investigation of the neighboring infrapatellar fat pad (Hoffa) was stimulated. While the density of sympathetic nerve fibers was higher in OA compared to AF (Fig. 4, left panel), the density of substance P-positive sensory nerve fibers was not different between groups (Fig. 4, middle panel). A relative preponderance of sensory over sympathetic nerve fibers in AF compared to OA could be detected when generating the density ratio of substance $\mathrm{P}$ positive divided by sympathetic nerve fibers (Fig. 4, left panel).

\section{Discussion}

To our best knowledge, this is the first study to investigate sensory and sympathetic nerve fiber densities in articular tissue in patients with AF of the knee. The density of sympathetic and sensory nerve fibers was generally higher in OA compared to AF, which probably demonstrates a higher degree of fibrotic scar formation in AF than OA tissue. In addition, in AF compared to $\mathrm{OA}$, in the anterior recess and in the infrapatellar fat pad, the density of sensory nerve fibers was higher in relation to the density of sympathetic nerve fibers. This indicates a preponderance of profibrotic sensory nerve fibers over antifibrotic sympathetic nerve fibers. This phenomenon seems to be located solely in anterior compartments.

Sensory hyperinnervation in relation to sympathetic innervation as a consequence of chronic mechanical or inflammatory stimulation of the tissue has been observed in several diseases: (1) osteonecrosis of the femoral head [28], (2) chronic pruritus and prurigo nodularis [29], (3) Charcot foot [30], (4) Dupuytren's contracture nodules [31], (5) painful Achilles tendinosis [32], and (6) rheumatoid arthritis [25]. Hyperinnervation can be a consequence of increased production of nerve growth factor which is often observed during inflammation [33]. In AF, early postoperative pain is often related to the ongoing arthrofibrotic process. Thus, we hypothesize that continuous stimulation of pain fibers induces inflammation, and inflammation itself stimulates relative sensory hyperinnervation leading to perpetuation of the process. This might be a possibility for a therapeutical approach of AF in order to perforate this vicious circle. So far, therapeutical strategies focus on closed or open manipulation and mobilization techniques under anesthesia and intense physiotherapy with appropriate pain medication. However, studies report of little success and an increased risk of another revision [34].

Substance P has a strong effect on fibroblast activation and extracellular matrix production leading to increased scar formation [35]. In addition, substance $\mathrm{P}$ is a proinflammatory neuropeptide that can aggravate a continuous inflammatory process: substance P stimulates IL-1 


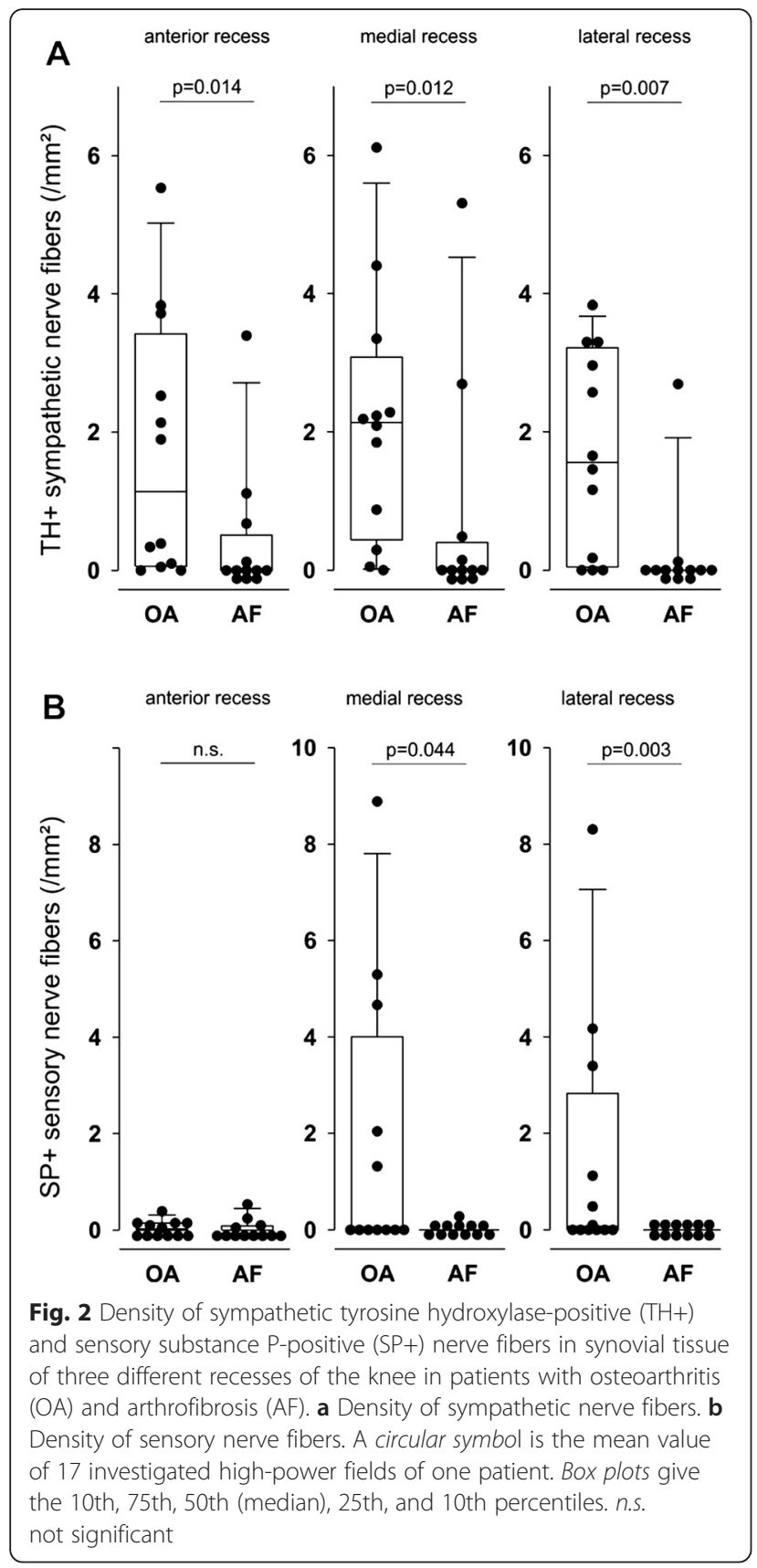

and tumor necrosis factor (TNF) from various cell types [36]. We recently demonstrated sprouting of substance P-positive nerve fibers in diseases with exaggerated fibrogenesis such as rheumatoid arthritis, Achilles tendinosis, and Dupuytren's contracture [25, 31, 32]. Sensory hyperinnervation and substance $\mathrm{P}$ might be important factors for aggravation and continuation of AF.

In contrast to substance $\mathrm{P}$, neurotransmitters of the sympathetic nerve endings can have anti-inflammatory effects at high neurotransmitter concentrations: norepinephrine binds preferentially $\alpha$-adrenoceptors (at high physiological concentrations also to $\beta$-adrenoceptors).

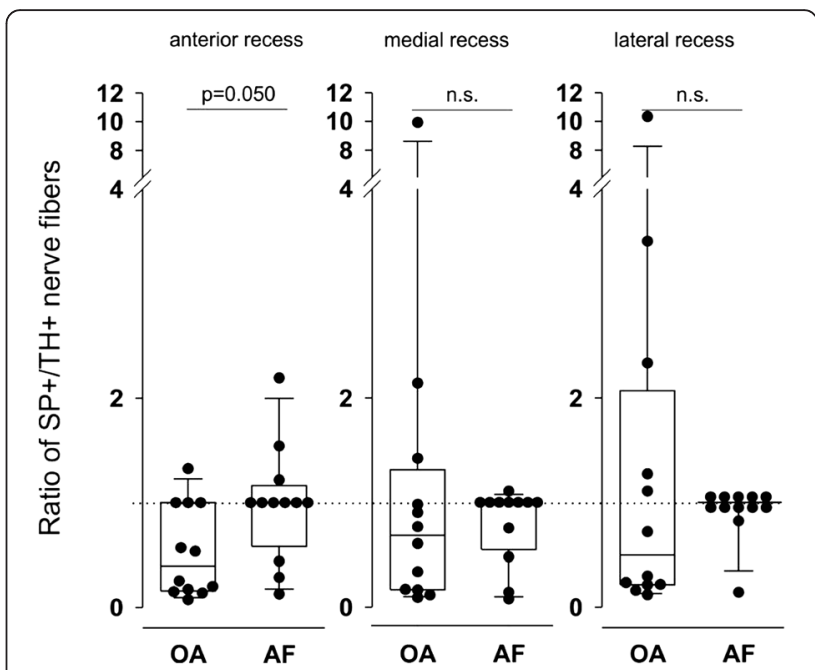

Fig. 3 Ratio of density of substance P-positive sensory nerve fibers $(\mathrm{SP}+)$ divided by density of tyrosine hydroxylase-positive sympathetic nerve fibers $(\mathrm{TH}+)$ in the three recesses of the knee joint. A circular symbol is the ratio of one individual patient. Box plots are explained in the legend of Fig. 2. AF arthrofibrosis, n.s. not significant, $O A$ osteoarthritis

Adenosine preferentially binds adenosine 1 (A1) receptors (at high physiological concentrations also to adenosine 2 (A2) receptors) [25, 31, 32]. Ligation of $\beta$ adrenoceptors or A2 adenosine receptors increase intracellular cyclic adenosine monophosphate (cAMP) levels and ligation of $\alpha 2$-adrenoceptors or A1 adenosine receptors decrease intracellular cAMP levels [25, 31, 32]. Generally, an elevated sympathetic tone due to increased firing rates at sympathetic nerves results in increased levels of norepinephrine and adenosine in the vicinity of the nerve terminal. This leads to an increase of intracellular cAMP in multiple peripheral target cells. Elevation of cAMP by these mechanisms has been repeatedly demonstrated to induce many anti-inflammatory effects on target immune mechanisms such as secretion of TNF or interferon- $\gamma[25,31,32]$. Thus, the presence of sympathetic nerves at a high fiber density would yield a high enough anti-inflammatory concentration of norepinephrine and adenosine [25, 31, 32]. In addition, sympathetic nerve terminals bear vesicles with endogenous opioids which are able to inhibit release of the proinflammatory substance P from sensory nociceptive nerve fibers [37]. In a highly inflammatory disease such as rheumatoid arthritis, the preponderance of substance P-positive nerve fibers over sympathetic nerve fibers is approximately $8: 1$, whereas in healthy tissue, the density of sensory versus sympathetic nerve fibers is balanced at 1:1 [25]. Taken together, the presence of sympathetic nerve fibers leading to high concentrations of sympathetic neurotransmitters can inhibit proinflammatory effects of substance $\mathrm{P}$, which might be also relevant in AF. 

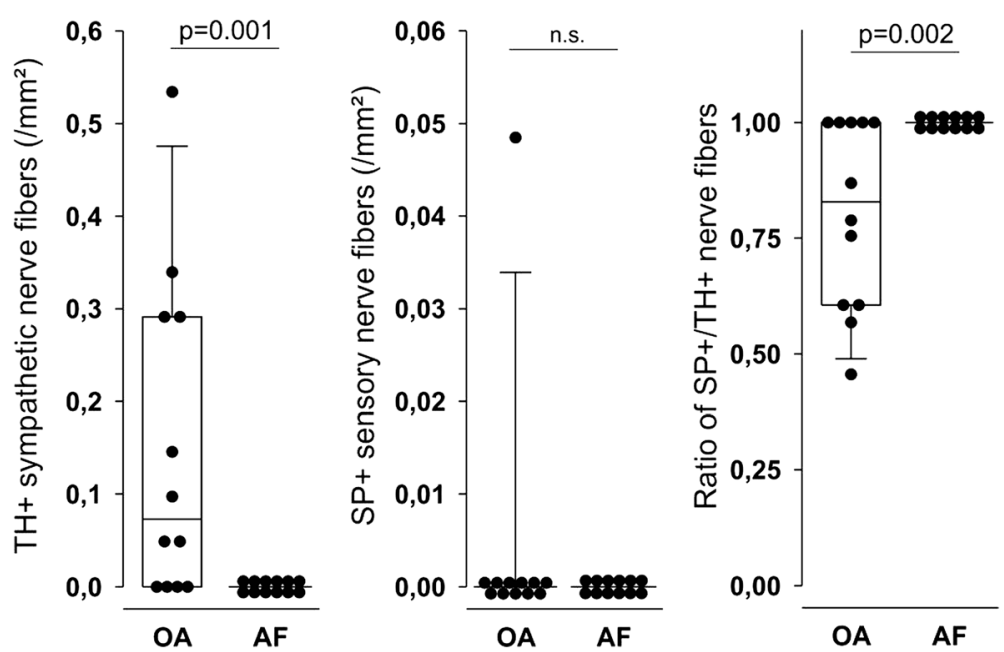

Fig. 4 Density of sympathetic tyrosine hydroxylase-positive $(\mathrm{TH}+)$ and sensory substance P-positive (SP+) nerve fibers in infrapatellar fat pad in patients with osteoarthritis (OA) and arthrofibrosis (AF). Box plots are explained in the legend of Fig. 2. n.s. not significant

However, the parallel investigation of sensory and sympathetic nerve fibers has never been reported in this TKA complication.

In the scenario of $\mathrm{AF}$, substance $\mathrm{P}$ is not a simple bystander but a strong profibrotic factor leading to fibroblast activation and extracellular matrix production [35, 38]. Substance $P$ is a proinflammatory neuropeptide that aggravates a continuous inflammatory process $[36,39]$. In the absence of anti-inflammatory catecholaminergic influences, substance $\mathrm{P}$ predominance might trigger a vicious circle leading to exaggerated scar formation. It is interesting that this phenomenon only appears in the anterior compartments of the anterior recess and the infrapatellar fat pad. Since the anterior compartments are more prone to mechanical stress, this region is particularly affected.

We are unable to describe the sequence of events and causality in humans because removal of tissue cannot be done in a serial way and manipulations of substance $\mathrm{P}$ release cannot be tested. Future studies might address this important aspect in animal models of AF as these models exist in rats and rabbits $[19,20]$. In these models, one might block the activity of substance $\mathrm{P}$ by specific receptor antagonists, or one might use tachykinin 1-deficient (Tac1-/-) mice (no SP) in order to specify the role of substance P. In the rat model, Watson et al. described that transforming growth factor beta is an outstandingly important stimulus of AF, which nicely fits to the fact that substance $\mathrm{P}$ is a perfect stimulator of this cytokine [40]. In addition, transforming growth factor beta stimulates the substance $P$ receptor in a way that the substance $\mathrm{P}$ signaling pathway is more active over a longer period of time [41]. Thus, the pain pathway and the fibrosis pathway are tightly coupled. This is also true for the presence of mast cells because substance $\mathrm{P}$ sensory nerve fibers are closely linked to mast cells, [34] and mast cells are predominant in fibrotic tissue not tested in the present study [42]. These aspects could serve as a foundation for the development of new drugs interrupting the abovementioned pathways. A limitation of this study might be the relatively small numbers of patients and controls. We also are aware that the ideal control group would be patients without OA which is also known as an inflammatory disease [30, 37]. But as described, this was not feasible due to ethical reasons and the fact that the needed volume of synovial tissue could not be acquired arthroscopically.

\section{Conclusions}

This study indicates that AF patients have hyperinnervation with sensory nerve fibers relative to sympathetic nerve fibers in the anterior compartments of the knee after total knee arthroplasty. Substance P of sensory nerve fibers is probably a critical element in this process because this neuropeptide has profibrotic capacities and stimulates transforming growth factor beta. Future studies in animal models of AF are needed to investigate the role of manipulation of the sensory nervous system.

\section{Competing interests \\ The authors declare that they have no competing interests.}

\section{Authors' contributions}

FXK and RHS conceived the study, participated in its design and

coordination, performed the statistical analyses, and drafted the manuscript. MS and HS carried out the immunohistochemistry, participated in the design of the study, organized the questionnaires, and performed the statistical analysis. $C B, J B$, and JG provided the patient material and helped in the data interpretation. All authors read and approved the final manuscript.

\section{Acknowledgements}

This study was partly supported by a grant from the Deutsche Forschungsgemeinschaft (STR 511/26-1). 


\section{Author details}

'MedArtes - Private Orthopaedic Clinic, Regensburger Strasse 13, 93073 Neutraubling, Germany. 'Laboratory of Experimental Rheumatology and Neuroendocrine Immunology, Department of Internal Medicine I, University Hospital Regensburg, Franz-Josef-Strauss-Allee 11, 93042 Regensburg, Germany. ${ }^{3}$ Department of Orthopedic Surgery, University of Regensburg, Kaiser-Karl-V.-Allee 3, 93073 Bad Abbach, Germany. ${ }^{4}$ Sportklinik Stuttgart, Taubenheimstrasse 8, 70372 Stuttgart, Germany.

\section{Received: 9 January 2016 Accepted: 11 February 2016}

\section{Published online: 17 February 2016}

\section{References}

1. Ritter MA, Berend ME, Meding JB, et al. 2001. Long-term followup of anatomic graduated components posterior cruciate-retaining total knee replacement. Clin Orthop Relat Res. (388): 51-57

2. Sextro GS, Berry DJ, Rand JA. 2001. Total knee arthroplasty using cruciateretaining kinematic condylar prosthesis. Clin Orthop Relat Res (388): 33-40

3. Mohtadi NG, Webster-Bogaert S, Fowler PJ. Limitation of motion following anterior cruciate ligament reconstruction. A case-control study. Am J Sports Med. 1991;19(6):620-4. discussion 624-5.

4. Boldt JG, Munzinger UK, Zanetti M, et al. Arthrofibrosis associated with total knee arthroplasty: gray-scale and power Doppler sonographic findings. AJR Am J Roentgenol. 2004;182(2):337-40. doi:10.2214/ajr.182.2.1820337.

5. Ipach I, Mittag F, Lahrmann J, et al. Arthrofibrosis after TKA influence factors on the absolute flexion and gain in flexion after manipulation under anaesthesia. BMC Musculoskelet Disord. 2011;12:184. doi:10.1186/1471-247412-184

6. Werner BC, Carr JB, Wiggins JC, et al. Manipulation under anesthesia after total knee arthroplasty is associated with an increased incidence of subsequent revision surgery. J Arthroplasty. 2015. doi:10.1016/j.arth.2015.01. 061.

7. Tjoumakaris FP, Tucker BC, Post Z, et al. Arthroscopic lysis of adhesions for the stiff total knee: results after failed manipulation. Orthopedics. 2014;37(5): e482-7. doi:10.3928/01477447-20140430-60.

8. Ghani H, Maffulli N, Khanduja V. Management of stiffness following total knee arthroplasty: a systematic review. Knee. 2012;19(6):751-9. doi:10.1016/j. knee.2012.02.010.

9. Sharkey PF, Lichstein PM, Shen C, et al. Why are total knee arthroplasties failing today has anything changed after 10 years? J Arthroplasty. 2014; 29(9):1774-8. doi:10.1016/j.arth.2013.07.024.

10. Lavernia CJ, Villa JM, lacobelli DA. What is the role of mental health in primary total knee arthroplasty? Clin Orthop Relat Res. 2015;473(1):159-63. doi:10.1007/s11999-014-3769-5.

11. Zeichen J, van Griensven M, Albers I, et al. Immunohistochemical localization of collagen VI in arthrofibrosis. Arch Orthop Trauma Surg. 1999; 119(5-6):315-8.

12. Unterhauser FN, Bosch U, Zeichen J, et al. Alpha-smooth muscle actin containing contractile fibroblastic cells in human knee arthrofibrosis tissue. Winner of the AGA-DonJoy Award 2003. Arch Orthop Trauma Surg. 2004; 124(9):585-91. doi:10.1007/s00402-004-0742-x.

13. Krenn V, Ruppert M, Knöß P, et al. Synovialitis vom arthrofibrotischen Typ: Kriterien eines neuen Synovialitis-Typus für die Diagnose der Arthrofibrose (Synovialitis of the arthrofibrotic type: criteria of a new synovialitis type for the diagnosis of arthrofibrosis). Z Rheumatol. 2013;72(3):270-8. doi:10.1007/ s00393-012-1076-7.

14. Freeman TA, Parvizi J, Della Valle CJ, et al. Reactive oxygen and nitrogen species induce protein and DNA modifications driving arthrofibrosis following total knee arthroplasty. Fibrogenesis Tissue Repair. 2009;2(1):5. doi: 10.1186/1755-1536-2-5

15. Pfitzner T, Geissler S, Duda G, et al. Increased BMP expression in arthrofibrosis after TKA. Knee Surg Sports Traumatol Arthrosc. 2012;20(9): 1803-8. doi:10.1007/s00167-011-1774-8.

16. Brown CA, Toth AP, Magnussen B. Clinical benefits of intra-articular anakinra for arthrofibrosis. Orthopedics. 2010;33(12):877. doi:10.3928/0147744720101021-09.

17. Bosch U, Zeichen J, Skutek M, et al. Arthrofibrosis is the result of a T cell mediated immune response. Knee Surg Sports Traumatol Arthrosc. 2001; 9(5):282-9. doi:10.1007/s001670100218.

18. Freeman TA, Parvizi J, Dela Valle CJ, et al. Mast cells and hypoxia drive tissue metaplasia and heterotopic ossification in idiopathic arthrofibrosis after total knee arthroplasty. Fibrogenesis Tissue Repair. 2010;3:17 doi:10.1186/1755-1536-3-17.

19. Emami MJ, Jaberi FM, Azarpira N, et al. Prevention of arthrofibrosis by monoclonal antibody against vascular endothelial growth factor: a novel use of bevacizumab in rabbits. Orthop Traumatol Surg Res. 2012;98(7): 759-64. doi:10.1016/j.otsr.2012.05.020.

20. Watson RS, Gouze E, Levings PP, et al. Gene delivery of TGF- $\beta 1$ induces arthrofibrosis and chondrometaplasia of synovium in vivo. Lab Invest. 2010; 90(11):1615-27. doi:10.1038/labinvest.2010.145.

21. Basbaum Al, Bautista DM, Scherrer $\mathrm{G}$, et al. Cellular and molecular mechanisms of pain. Cell. 2009;139(2):267-84. doi:10.1016/j.cell.2009.09.028.

22. Bellamy N, Buchanan WW, Goldsmith $\mathrm{CH}$, et al. Validation study of WOMAC a health status instrument for measuring clinically important patient relevant outcomes to antirheumatic drug therapy in patients with osteoarthritis of the hip or knee. J Rheumatol. 1988:15(12):1833-40.

23. Insall JN, Dorr LD, Scott RD, et al. 1989. Rationale of the Knee Society clinical rating system. Clin Orthop Relat Res. (248): 13-14

24. Roos EM, Roos HP, Lohmander LS, et al. Knee Injury and Osteoarthritis Outcome Score (KOOS) development of a self-administered outcome measure. J Orthop Sports Phys Ther. 1998;28(2):88-96. doi:10.2519/jospt. 1998.28.2.88.

25. Weidler C, Holzer C, Harbuz M, et al. Low density of sympathetic nerve fibres and increased density of brain derived neurotrophic factor positive cells in RA synovium. Ann Rheum Dis. 2005;64(1):13-20. doi:10.1136/ard. 2003.016154.

26. Miller LE, Grifka J, Schölmerich J, et al. Norepinephrine from synovial tyrosine hydroxylase positive cells is a strong indicator of synovial inflammation in rheumatoid arthritis. J Rheumatol. 2002:29(3):427-35.

27. Lehner B, Koeck FX, Capellino S, et al. Preponderance of sensory versus sympathetic nerve fibers and increased cellularity in the infrapatellar fat pad in anterior knee pain patients after primary arthroplasty. J Orthop Res. 2008; 26(3):342-50. doi:10.1002/jor.20498.

28. Beckmann J, Knödl M, Bauser E, et al. Loss of sympathetic nerve fibers in vital intertrochanteric bone cylinders lateral to osteonecrosis of the femoral head. Joint Bone Spine. 2013;80(2):188-94. doi:10.1016/j.jbspin.2012.03.003.

29. Haas S, Capellino S, Phan NQ et al. Low density of sympathetic nerve fibers relative to substance P-positive nerve fibers in lesional skin of chronic pruritus and prurigo nodularis. J Dermatol Sci. 2010;58(3):193-7. doi:10.1016/j.jdermsci.2010.03.020.

30. Koeck F, Bobrik V, Fassold A, et al. Marked loss of sympathetic nerve fibers in chronic Charcot foot of diabetic origin compared to ankle joint osteoarthritis. J Orthop Res. 2009;27(6):736-41. doi:10.1002/jor. 20807

31. Schubert TEO, Weidler C, Lerch K, et al. Achilles tendinosis is associated with sprouting of substance P positive nerve fibres. Ann Rheum Dis. 2005;64(7): 1083-6. doi:10.1136/ard.2004.029876.

32. Schubert TEO, Weidler C, Borisch N, et al. Dupuytren's contracture is associated with sprouting of substance $P$ positive nerve fibres and infiltration by mast cells. Ann Rheum Dis. 2006;65(3):414-5. doi:10.1136/ard.2005.044016

33. Aloe L, Tuveri MA, Carcassi $U$, et al. Nerve growth factor in the synovial fluid of patients with chronic arthritis. Arthritis Rheum. 1992;35(3):351-5.

34. Stead RH, Dixon MF, Bramwell NH, et al. Mast cells are closely apposed to nerves in the human gastrointestinal mucosa. Gastroenterology. 1989;97(3): 575-85.

35. Burssens $P$, Steyaert A, Forsyth $R$, et al. Exogenously administered substance $P$ and neutral endopeptidase inhibitors stimulate fibroblast proliferation, angiogenesis and collagen organization during Achilles tendon healing. Foot Ankle Int. 2005;26(10):832-9.

36. Lotz M, Vaughan $\mathrm{JH}$, Carson DA. Effect of neuropeptides on production of inflammatory cytokines by human monocytes. Science. 1988;241(4870): $1218-21$.

37. Konttinen $Y T$, Kemppinen $P$, Segerberg $M$, et al. Peripheral and spinal neural mechanisms in arthritis, with particular reference to treatment of inflammation and pain. Arthritis Rheum. 1994;37(7):965-82.

38. Katayama I, Nishioka K. Substance P augments fibrogenic cytokine-induced fibroblast proliferation: possible involvement of neuropeptide in tissue fibrosis. J Dermatol Sci. 1997:15(3):201-6.

39. Lieb K, Fiebich BL, Berger $M$, et al. The neuropeptide substance $P$ activates transcription factor NF-kappa B and kappa B-dependent gene expression in human astrocytoma cells. J Immunol. 1997;159(10):4952-8. 
40. Lai X, Wang Z, Zhu J, et al. Effect of substance $P$ on gene expression of transforming growth factor beta-1 and its receptors in rat's fibroblasts. Chin J Traumatol. 2003;6(6):350-4.

41. Beinborn M, Blum A, Hang L, et al. TGF-beta regulates T-cell neurokinin-1 receptor internalization and function. Proc Natl Acad Sci USA. 2010;107(9): 4293-8. doi:10.1073/pnas.0905877107.

42. Monument MJ, Hart DA, Befus AD, et al. The mast cell stabilizer ketotifen reduces joint capsule fibrosis in a rabbit model of post-traumatic joint contractures. Inflamm Res. 2012;61(4):285-92. doi:10.1007/s00011-011-0409-3.

Submit your next manuscript to BioMed Central and we will help you at every step:

- We accept pre-submission inquiries

- Our selector tool helps you to find the most relevant journal

- We provide round the clock customer support

- Convenient online submission

- Thorough peer review

- Inclusion in PubMed and all major indexing services

- Maximum visibility for your research

Submit your manuscript at www.biomedcentral.com/submit 